Int. J. Morphol.,

32(1):245-250, 2014

\title{
How do Different Sporting Activities Affect Bone Patella Volume? A Descriptive Pilot Study
}

\author{
¿Como Afectan las Diferentes Actividades Deportivas el Volumen \\ de la Patela? Un Estudio Piloto Descriptivo
}

Karalezli, N.. .; Bozkurt, I.**; Unver Dogan, N. ${ }^{* * *}$ \& Kerimoglu, U.****

KARALEZLI, N.; BOZKURT, I.; UNVER DOGAN, N. \& KERIMOGLU, U. How do different sporting activities affect bone patella volume? A descriptive pilot study. Int. J. Morphol., 32(1):245-250, 2014.

SUMMARY: The aim of this study was to compare the patella bone volume of sedentary men with that of elite male sportspeople, including judoka, cyclists, weightlifters, and taekwondo athletes who were members of Turkish National Professional Teams. All subjects had no history or clinical signs of an orthopaedic disorder such as osteoarthritis or acromegaly. The right and left knees of all groups were placed side by side in a supine position and were scanned by high resolution imaging with multidetector computed tomography. The differences between the volume of right and left patellae of sedentary men, judoka, cyclists, weightlifters, and taekwondo athletes were statistically significant. The average left patella of a professional cyclist and the average right patella volume of a sedentary man were maximum and minimum, respectively. The results demonstrated that the patella volume of cyclists was significantly larger. According to the literature, patella bone volume was associated with a reduced rate of annual patella cartilage volume loss, so cycling early in life may prevent patella cartilage loss in the future.

KEY WORDS: Patella bone volume; Cyclist, Judoka; Weightlifter; Taekwondo athlete.

\section{INTRODUCTION}

The patella is the largest sesamoid bone in the human body and is embedded in the tendon of quadriceps femoris, anterior to the knee joint (Moore, 1992; Standring, 2005). It is flat, distally triangular, proximally curved, and has anterior and posterior surfaces, three borders, and an apex. In the living, its distal apex is a little proximal to the line of the knee joint when standing (Standring).

Although studies usually focus on the tibiofemoral joint, cartilage loss of this large sesamoid bone is a major source of pain in knee osteoarthritis. Wijayaratne et al. (2008) report that there is a relationship between patella bone volume and patella cartilage volume loss.

The aim of this study was to compare patella bone volume in sedentary men and professional athletes of four different sports (cycling, judo, weightlifting, and taekwondo), all of whom had no knee pain or any other knee pathology.

\section{MATERIAL AND METHOD}

Subjects. This study was performed with eight right and left knees of sedentary men (mean age: $21.62 \pm 1.41$ ) and eight right and left knees of elite male Judoka (mean age: $21.12 \pm 2.75$ ), cyclists (mean age: $21.62 \pm 1.28$ ), weightlifters (mean age: $21.62 \pm 1.99$ ), and taekwondo athletes (mean age: 22.37 \pm 1.77$)$ who were members of Turkish National Professional Teams, all of whom had no history or clinical signs of an orthopedic disorder such as osteoarthritis or acromegaly.

The athletes in this study group had been performing their sports for at least ten years with an average of 20 hours training a week.

The procedures followed were compatible with the ethical standards of the responsible committee on human experimentation of the faculty, which are based on the Helsinki Declaration.

\footnotetext{
* Department of Orthophedics, Meram Medical Faculty, Necmettin Erbakan University, Konya, Turkey.

** Physical Education Teaching Department, Physical Education and Sport Vocational School, Selcuk University, Konya, Turkey.

**** Department of Anatomy, Medical Faculty, Selcuk University, Konya, Turkey.

***** Department of Radiology, Meram Medical Faculty, Necmettin Erbakan University, Konya, Turkey.
} 
Radiographic evaluation. The right and left knees of all groups were placed side by side in a supine position and were scanned by high resolution imaging with multidetector computed tomography (MDCT) (Somatom Sensation 64; Siemens Medical Solution, Forchheim, Germany). Scanning along the knee joint, including the entire patella, was performed by using the following parameters: detector collimation, $64 \mathrm{x} 1 \mathrm{~mm}$; section thickness, $1 \mathrm{~mm}$ (increment, $1 \mathrm{~mm}$ ); gantry rotation time, $330 \mathrm{msec} ; \mathrm{kVp}, 120 ; \mathrm{mA}, 300$; and spatial resolution, $512 \times 512$ pixels with pixel spacing. Dose and scanning parameters were prepared by a musculoskeletal radiologist. Axial images were evaluated through volume measuring software on the workstation. Axial images of each patella were evaluated separately, and the area was drawn manually by the radiologist using the software (Fig. 1). After measuring all the axial images, the software measured the volume of the patellae automatically and showed the total volume by coloring the region of interest (Fig. 2).

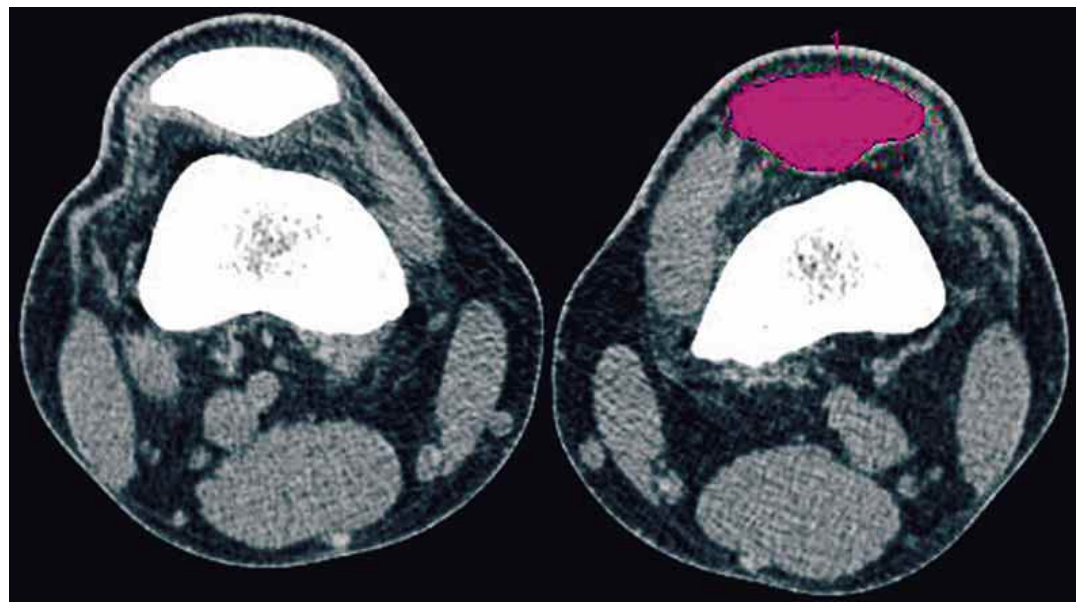

Fig. 1. Transverse computed tomography image demonstrates one section for the manual drawing of the patella area.

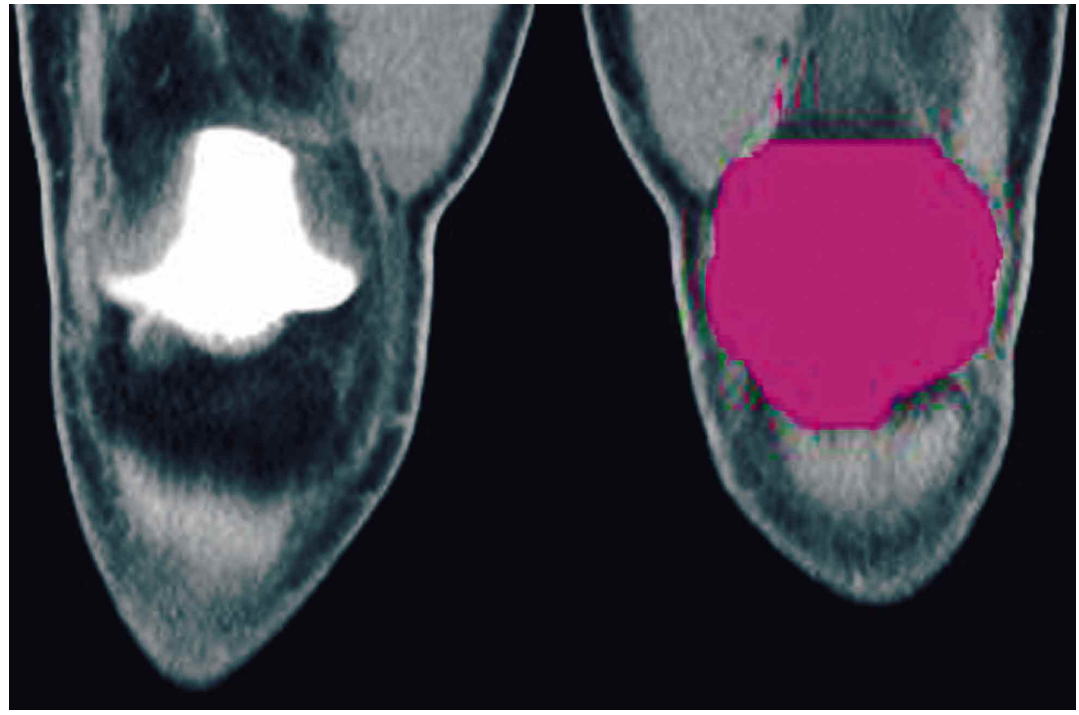

Fig. 2. Coronal computed tomography image, which is given automatically by the volume software of the workstation, demonstrates the volume after drawing the area of the patella in all transverse sections.
Statistical Analysis. Statistical analyses were performed with one-way analysis of variance and Tukey's test for individual comparisons. Statistical analysis between groups was performed with ANOVA, and $\mathrm{p}$ values of $<0.05$ (two-tailed) were regarded as statistically significant (SPSS Version 14.0, Chicago, USA).

\section{RESULTS}

The characteristics of the study groups (sedentary, Judoka, cyclist, weightlifter, taekwondo athlete) are presented in Table I.

The average volume of the right and left patella bone in different groups is presented in Table II. The average left patella of professional cyclists and the average right patella volume of sedentary groups were maximum and minimum, respectively.

The statistical analysis of average volume of the right and left patella bone in different groups is presented in Table III. The differences between the volume of right and left patellae of sedentary men, judoka, cyclists, weightlifters, and taekwondo athletes were statistically significant $(\mathrm{P}<0.05)$.

The statistical analysis of average volume of the right patella bone between groups showed that the difference was statistically significant $(\mathrm{P}<0.05)$ between cyclists and sedentary men, cyclists and judoka, and cyclists and weightlifters (Table IV).

The statistical analysis of average volume of the left patella bone between groups showed that the difference was statistically significant $(\mathrm{P}<0.05)$ between cyclists and sedentary men, cyclists and judoka, cyclists and weightlifters, and taekwondo athletes and sedentary men (Table V). 
Table I. Physical characteristics of subjects

\begin{tabular}{|c|c|c|c|c|c|c|c|c|c|c|}
\hline & \multicolumn{2}{|c|}{ Sedentery } & \multicolumn{2}{|c|}{ Cyclist } & \multicolumn{3}{|c|}{ Weight-lifter } & \multicolumn{2}{|c|}{ Teakwondo } & \multirow{2}{*}{$\begin{array}{l}\text { Judoist } \\
\text { St. Dev. }\end{array}$} \\
\hline & Mean & St. Dev. & Mean & St. Dev. & Mean & St. Dev. & Mean & St. Dev. & Mean & \\
\hline Length $(\mathrm{cm})$ & 173,37 & 4,96 & 179,3 & 5,44 & 174,50 & 4,66 & 176,0 & 4,93 & 174,25 & 8,99 \\
\hline Weight(kg) & 65,50 & 5,24 & 69,75 & 4,83 & 75,50 & 8,64 & 68,75 & 10,91 & 74,50 & 20,06 \\
\hline Age (year) & 21,62 & 1,41 & 22,25 & 1,28 & 21,62 & 1,1 & 22,37 & 1,77 & 21,12 & 2,75 \\
\hline
\end{tabular}

Table II. The average volume of the right and left patellar bone in different groups

\begin{tabular}{lcccccccccc}
\hline & \multicolumn{2}{c}{ Sedentery } & \multicolumn{2}{c}{ Cyclist } & \multicolumn{2}{c}{ Weight-lifter } & \multicolumn{2}{c}{ Teakwondo } & \multicolumn{2}{c}{ Judoist } \\
& \multicolumn{2}{c}{$\mathrm{N}=8$} & \multicolumn{2}{c}{$\mathrm{N}=8$} & \multicolumn{2}{c}{$\mathrm{N}=8$} & & $\mathrm{~N}=8$ & $\mathrm{~N}=8$ \\
\hline & Mean & St. Dev. & Mean & St. Dev. & Mean & St. Dev. & Mean & St. Dev. & Mean & St. Dev. \\
\hline Right patella $\mathrm{g} / \mathrm{cm}^{2}$ & 22,10 & 2,131 & 29,31 & 3,701 & & 3,384 & 26,25 & 3,311 & 23,10 & 3,291 \\
Left patella $\mathrm{g} / \mathrm{cm}^{2}$ & 21,68 & 1,426 & 29,71 & 2,19 & 24,13 & 3,71 & 27,12 & 4,238 & 23,45 & 4,38 \\
\hline
\end{tabular}

Table III. The statistical analysis of average volume of the right and left patellar bone in between branches.

\begin{tabular}{ccccccc}
\hline & & Sum of Squares & df & Mean Square & F & Sig. \\
\hline Right patella & Between branches & 263,072 & 4 & 65,768 & 6,386 &, 001 \\
Left patella & Between branches & 320,722 & 4 & 80,180 & 6,935 &, 000 \\
\hline
\end{tabular}

Table IV. The statistical analysis of average volume of the right patellar bone between groups.

\begin{tabular}{lllll}
\hline & Judoist & Teakwondo & Weight-lifter & Cyclist \\
\hline Sedentery & 0.97 & 0.095 & 0.713 & $0.001^{*}$ \\
Cyclist & $0.004^{*}$ & 0.333 & $0.021^{*}$ & \\
Weight-lifter & 0.967 & 0.681 & & \\
Teakwondo & 0.306 & & & \\
\hline
\end{tabular}

Table V. The statistical analysis of average volume of the left patellar bone between groups.

\begin{tabular}{lllll}
\hline & Judoist & Teakwondo & Weight-lifter & Cyclist \\
\hline Sedentery & 0.835 & $0.023^{*}$ & 0.503 & $0.000^{*}$ \\
Cyclist & $0.007^{*}$ & 0.556 & $0.028^{*}$ & \\
Weight-lifter & 0.979 & 0.511 & & \\
Teakwondo & 0.218 & & & \\
\hline
\end{tabular}

\section{DISCUSSION}

Taekwondo, which is a very popular martial arts sport, is an activity that requires many skills, a high-energy demand, and sophisticated techniques. Therefore, technical and vigorous physical exercises should be included in the training program. Technical training is based on specific training, including running, rope skipping, or racket-hitting that are classical exercises, which are not varied (Bouhlel et al., 2006). Olympic weightlifting has been demonstrated to be a typical short-term explosive event, with a training regimen that consists mainly of competitive lifting tasks with heavy resistance loads (Garhammer, 1980; Kanehisa \& Fukunaga, 1999). It has been found that the changes in 
muscle function with training reflect the type of muscle activity during exercise (Sale \& MacDougall, 1981; Kanehisa \& Fukunaga). Judo is an Olympic sport that is practiced worldwide (Artioli et al., 2010) and characterized by brief bouts of high-intensity intermittent-exercise that requires energy providing (Chaouachi et al., 2009). Cycling is one of the most popular means of transportation, recreation, fitness, and sport among millions of people of all ages who ride on road and off road, using a variety of bicycle types including mountain, touring, racing, stunt, and stationary exercise bicycles. Cycling is a readily available, economical and efficient form of aerobic nonimpact exercise with established cardiovascular beneficial effects (Leibovitch \& Mor, 2005). The forces, load moments, and muscular power output acting on and about the hip, knee and ankle joints during cycling were determined using cine-film, pedal force measurements, and biomechanical calculations based upon static and dynamic mechanics (Ericson, 1986).

National team athletes who participate in any of these sports partake in serious physical exercise for years. According to the literature, exercises involving high intensity and high strain rates are more osteogenic than lowintensity endurance-type activities (Heinonen et al., 1996; Nikander et al., 2006; Karinkanta et al., 2007; Rantalainen et al., 2009). The data in this particular study is comparable with the literature that patella volume was found to be larger in all sporting groups than in the sedentary group. Of all these groups, cycling seems to have more osteogenic effect on the patella because cyclists have the largest bone volume. Is this result important for us and, if so, why?

Osteoarthritis (OA) is a common joint disease characterized by changes to the integrity of articular cartilage and subchondral bone (Foley et al., 2007; Hanna et al., 2007). The knee is the most frequently affected joint, with a prevalence of $30 \%$ in older people (Foley et al.).

Patella cartilage volume has been shown to correlate with radiologic grade of patellofemoral OA. While patella cartilage volume is lost at a rate of $1.6 \%$ per year among middle-aged women with no clinical knee OA (Wijayaratne et al.), the rate is between $3.7 \%$ and $5.3 \%$ per year in OA (Hanna et al., 2007). Several factors affect the patella cartilage change, but until Wijayaratne et al., no previous study showed the relationship between patella bone volume and patella cartilage volume loss. In this study, the authors have demonstrated that baseline patella bone volume was associated with a reduced rate of annual patella cartilage volume loss (Wijayaratne et al.). We can therefore say that cyclists will likely have less patella volume loss than the other athletes.
In this particular study, the patella volumes of the right and left knees were different between the groups. It was probably because of individual characteristics that one extremity may be stronger than the other, even in national players.

Patella cartilage volumes and defects were investigated using magnetic resonance images (Hanna et al., 2006; Kessler et al., 2006; Hanna et al., 2007; Teichtahl et al., 2008; Wijayaratne et al.). Computed tomography is an effective diagnostic modality for 2D multiplanar images of bone structures, including their defects. The MDCT, a recent technological advantage, can obtain a large number of 2D images during one rotation of X-ray tube, making it possible to get thin slices within a short scan time (Kalayci, 2008). Therefore, we used MDCT to obtain the images.

In recent years, cycling has been used in clinical settings to successfully rehabilitate traumatic knee injuries in athletes (Flynn \& Soutas-Little, 1993; Cipriani et al., 1995; Eisner et al., 1999). Researchers hypothesize that cycling backwards on a cycle ergometer increases muscle fiber activation of the lower-extremity musculature, improving strength. Consequently, researchers are investigating the efficacy of backward cycling as an effective rehabilitative tool following surgery in athletes with serious knee injuries (Eisner et al.). Furthermore, some authors have suggested that cycling might be a useful exercise in the rehabilitation of patients with injuries to the anterior cruciate ligament, medial collateral ligament of the knee, or Achilles tendon (Ericson).

Our study must be viewed in the light of some limitations. The main shortcoming of the present study was the lack of a larger number of patellae for stronger statistical conclusions. However, to the best of our knowledge, this is the first report that compares national athletes of four different sports who have been performing their specific sport for at least ten years.

\section{CONCLUSION}

The results demonstrated that the patella volume of cyclists was significantly larger than the other sportspeople and sedentary men. According to the literature, patella bone volume was associated with a reduced rate of annual patella cartilage volume loss, which indicates that cycling at an early age may prevent patella cartilage loss in the future. Of course, further studies are needed to confirm our results.

ACKNOWLEDGMENTS The authors received no grant or sources of financial support related to the topic or topics of this article. 
KARALEZLI, N.; BOZKURT, I.; UNVER DOGAN, N. \& KERIMOGLU, U. ¿Como afectan las diferentes actividades deportivas el volumen de la patela? Un estudio piloto descriptivo. Int. J. Morphol., 32(1):245-250, 2014.

RESUMEN: El objetivo de este estudio fue comparar el volumen de la patela en hombres sedentarios con la patela de deportistas de elite, incluyendo judokas, ciclistas, levantadores de pesas y atletas de taekwondo, miembros de equipos profesionales nacionales turcos. Los sujetos del estudio no tenían antecedentes o signos clínicos de una enfermedad ortopédica como la osteoartritis. Las rodillas derecha e izquierda de los individuos de todos los grupos se colocaron una al lado de otra, en posición supina y fueron escaneadas por tomografía computarizada multidetector de alta resolución. Las diferencias entre el volumen de la patela derecha e izquierda de los hombres sedentarios, atletas judokas, ciclistas, levantadores de pesas y atletas de taekwondo fueron estadísticamente significativas. El volumen promedio de la patela izquierda de un ciclista profesional y el volumen promedio de la patela derecha de un hombre sedentario fueron de máximo y mínimo, respectivamente. Los resultados demostraron que el volumen de la patela de ciclistas fue significativamente mayor. De acuerdo a la literatura, el volumen del hueso de la patela fue asociado con una pérdida anual de volumen del cartílago, razón por la cual el ciclismo en una edad temprana puede prevenir la pérdida de cartílago de la patela en el futuro.

PALABRAS CLAVE: Volumen de la patela; Ciclista; Judoka; Levantador de pesas; Atleta de taekwondo.

\section{REFERENCES}

Artioli, G. G.; Iglesias, R. T.; Franchini, E.; Gualano, B.; Kashiwagura, D. B.; Solis, M.Y.; Benatti, F. B.; Fuchs, M., \& Lancha Junior, A. H. Rapid weight loss followed by recovery time does not affect judo-related performance. J. Sports Sci., 28(1):21-32, 2010.

Bouhlel, E.; Jouinia, A.; Gmadaa, N.; Nefzi, A.; Ben Abdallah, K. \& Tabka, Z. Heart rate and blood lactate responses during Taekwondo training and competition. Sci. Sports, 21(5):28590, 2006.

Chaouachi, A.; Coutts, A. J.; Chamari, K.; Wong, del P.; Chaouachi, M.; Chtara, M.; Roky, R. \& Amri, M. Effect of Ramadan intermittent fasting on aerobic and anaerobic performance and perception of fatigue in male elite judo athletes. J. Strength Cond. Res., 23(9):2702-9, 2009.

Cipriani, D. J.; Armstrong, C. W. \& Gaul, S. Backward walking at three levels of treadmill inclination: an electromyographic and kinematic analysis. J. Orthop. Sports Phys. Ther., 22(3):95$102,1995$.

Eisner, W. D; Bode, S. D.; Nyland, J. \& Caborn, D. N. Electromyographic timing analysis of forward and backward cycling. Med. Sci. Sports Exer., 31(3):449-55. 1999.

Ericson, M. On the biomechanics of cycling. A study of joint and muscle load during exercise on the bicycle ergometer. Scand. J. Rehabil. Med. (Suppl), 16:1-43, 1986.

Flynn, T. W. \& Soutas-Little, R. W. Mechanical power and muscle action during forward and backward running. J. Orthop. Sports Phys. Ther, 17(2):108-12, 1993.

Foley, S.; Ding, C.; Cicuttini, F. \& Jones, G. Physical activity and knee structural change: a longitudinal study using MRI. Med. Sci. Sports Exer., 39(3):426-34, 2007.
Garhammer, J. Power production by Olympic weightlifters. Med. Sci. Sports Exerc., 12(1):54-60, 1980.

Hanna, F.; Wluka, A. E.; Ebeling, P. R.; O'Sullivan, R.; Davis, S. R. $\&$ Cicuttini, F. M. Determinants of change in patella cartilage volume in healthy subjects. J. Rheumatol., 33(8):1658-61, 2006.

Hanna, F. S.; Bell, R. J.; Davis, S. R.; Wluka, A. E.; Teichtahl, A. J.; O'Sullivan, R. \& Cicuttini, F. M. Factors affecting patella cartilage and bone in middle-aged women. Arthritis Rheum., 57(2):272-8,2007.

Heinonen, A.; Kannus, P.; Sievänen, H.; Oja, P.; Pasanen, M.; Rinne, M.; Uusi-Rasi, K., \& Vuori, I. Randomised controlled trial of effect of high-impact exercise on selected risk factors for osteoporotic fractures. Lancet, 348(9038):1343-7, 1996.

Kalayci, I. 3D reconstruction of phalangeal and metacarpal bones of male judo players and sedentary men by MDCT images. $J$. Sports Sci. Med., 7(4):544-8, 2008.

Kanehisa, H. \& Fukunaga, T. Profiles of musculoskeletal development in limbs of college Olympic weightlifters and wrestlers. Eur. J. Appl. Physiol. Occup. Physiol., 79(5):41420, 1999.

Karinkanta, S.; Heinonen, A.; Sievänen, H.; Uusi-Rasi, K.; Pasanen, M.; Ojala, K.; Fogelholm, M. \& Kannus, P. A multi-component exercise regimen to prevent functional decline and bone fragility in home-dwelling elderly women: randomized, controlled trial. Osteoporos. Int., 18(4):453-62, 2007.

Kessler, M. A.; Glaser, C.; Tittel, S.; Reiser, M. \& Imhoff, A. B. Volume changes in the menisci and articular cartilage of runners: an in vivo investigation based on 3-D magnetic resonance imaging. Am. J. Sports Med., 34(5):832-6, 2006. 
KARALEZLI, N.; BOZKURT, I.; UNVER DOGAN, N. \& KERIMOGLU, U. How do different sporting activities affect bone patella volume? A descriptive pilot study. Int. J. Morphol., 32(1):245-250, 2014.

Leibovitch, I. \& Mor, Y. The vicious cycling: bicycling related urogenital disorders. Eur. Urol., 47(3):277-86,2005.

Moore, K. L. Clinically Oriented Anatomy. $3^{\text {th }}$ ed. Baltimore, Williams \& Wilkins, 1992. p.388.

Nikander, R.; Sievänen, H.; Uusi-Rasi, K.; Heinonen, A. \& Kannus, P. Loading modalities and bone structures at nonweight-bearing upper extremity and weight-bearing lower extremity: a pQCT study of adult female athletes. Bone, 39(4):886-94,2006.

Rantalainen, T.; Heinonen, A.; Linnamo, V.; Komi, P.V.; Takala, T. E. \& Kainulainen, H. Short-term bone biochemical response to a single bout of high-1mpact exercise. J. Sports Sci. Med., 8(4):553-9, 2009.

Sale, D. \& MacDougall, D. Specificity in strength training: a review for the coach and athlete. Can. J. Appl. Sport Sci., 6(2):8792,1981 .

Standring, S. M. Gray's Anatomy. $39^{\text {th }}$ ed. Edinburgh, Churchill Livinstone, 2005. pp.1471-2.

Teichtahl, A. J.; Wang, Y.; Wluka, A.E.; Szramka, M.; English, D. R.; Giles, G. G.; O'Sullivan, R. \& Cicuttini, F. M. The longitudinal relationship between body composition and patella cartilage in healthy adults. Obesity (Silver Spring), 16(2):4217, 2008.

Wijayaratne, S. P.; Teichtahl, A. J.; Wluka, A. E.; Hanna, F.; Bell, R.; Davis, S. R.; Adams, J. \& Cicuttini, F. M. The determinants of change in patella cartilage volume-a cohort study of healthy middle-aged women. Rheumatology (Oxford), 47(9):14269,2008 .
Correspondence to:

Nadire Unver Dogan

Department of Anatomy

Medical Faculty

Selcuk University

42075, Konya

TURKEY

Email: nunver2003@yahoo.com

Received: 19-07-2013

Accepted: 24-12-2013 